\title{
La mediación británica en la guerra entre las Provincias Unidas y el Imperio de Brasil (1826-1828): una mirada desde Montevideo
}

ANA FREGA*

Resumo: $\mathrm{O}$ artigo retoma um tema que tem sido objeto de fortes polêmicas historiográficas, tais como a participação da Grã-Bretanha na independência do Uruguai, e o estuda da perspectiva do cônsul britânico em Montevidéu. Nessa direção, através da análise dos relatórios consulares de Thomas S. Hood, abordamse aspectos tais como a disparidade dos interesses britânicos na região e o percurso das posturas independentistas.

Abstract: This article focuses on a controversial topic that has already been discussed in the area of Historiography: the participation of Great Britain on the independence of Uruguay. Here we study the perspective of the British consul in Montevideo. On this line of work, through the analysis of the consular reports of Thomas S. Hood, we approach the disparity of the British interests on the area and the course of the pro-independence stances.

Palavras-chave: Independência do Uruguai. Região platina. Interesses britânicos.

Key words: Independence of Uruguay. River Plate region. British interests.

\section{Introducción}

La mediación de Gran Bretaña en la guerra entre las Provincias Unidas y el Imperio de Brasil que culminó con la independencia de la "Provincia de Montevideo, llamada hoy Cisplatina"1 ha sido objeto

* Profesora titular del Departamento de Historia del Uruguay de la Facultad de Humanidades y Ciencias de la Educación, Universidad de la República en Montevideo, Uruguay. Doctora en Historia por la Universidad de Buenos Aires.

1 De esta forma se denomina el territorio declarado independiente en la Convención Preliminar de Paz suscrita en Río de Janeiro por los delegados del Emperador de Brasil y de la República de las Provincias Unidas el 27 de agosto de 1828, con la mediación de Gran Bretaña. Ver el documento en ARMAND UGON, E.; CERDEIRAS ALONSO, J. C.; ARCOS FERRAND, L.; GOLDARACENA, C. República Oriental del Uruguay. Compilación de leyes y decretos, 1825-1930. Tomo I. 18251834. Montevideo: 1930 , p. $84-89$.

Estudos Ibero-Americanos, PUCRS, v. XXXIV, n. 1, p. 36-64, junho 2008 
de una fuerte polémica que trasciende el ámbito historiográfico. La formación de un estado independiente en la ribera norte del Río de la Plata, entre las Provincias Unidas y el Imperio de Brasil, ha sido interpretada de maneras tan extremas que van desde la consagración de un "destino" hasta una "invención británica", con variantes intermedias. Este artículo se propone transitar un camino diferente, inscribiendo la independencia del Uruguay en el marco de los procesos de construcción estatal en el Río de la Plata y Brasil y "como uno de los remolinos problemáticos que amenazaban el precario equilibrio logrado en el costado occidental del mundo tras la derrota de Napoleón" . ${ }^{2}$ Por ello, apuntamos aquí a enriquecer el conocimiento de la mediación británica a través de la mirada de quienes si bien más alejados de los centros de toma de decisiones, eran directamente afectados por ellas.

En este sentido, partimos de una breve exposición acerca del tratamiento historiográfico del tema, para luego presentar los intereses británicos en Montevideo y las distintas alternativas de organización del espacio rioplatense a partir de una selección de los informes del cónsul británico en Montevideo entre 1824 y 1829. ${ }^{3}$ Aún con su carácter parcial y sesgado, esta documentación permite una aproximación a las variaciones de opinión, los proyectos, las acciones, los temores y las esperanzas de los distintos bandos. Se ha recurrido también a testimonios de viajeros y comerciantes británicos como John Hall, autor de un informe sobre la situación de la Provincia elaborado para Hood ${ }^{4}$ y a las noticias y opiniones recogidas en periódicos como The British Packet ${ }^{5}$, editado en inglés en Buenos Aires y The Times ${ }^{6}$, publicado en Londres, a efectos de

2 REAL DE AZÚA, Carlos. Los orígenes de la nacionalidad uruguaya. Montevideo: Arca/ Nuevo Mundo, 1990, p. 372.

3 BARRÁN, José Pedro, FREGA, Ana; NICOLIELLO, Mónica. El Cónsul Británico en Montevideo y la independencia del Uruguay. Selección de los informes de Thomas Samuel Hood (1824-1829). Montevideo: Dpto. de Publicaciones de la Universidad de la República, 1999. La investigación en los archivos de Londres fue realizada por Barrán.

4 MINISTERIO DE EDUCACIÓN Y CULTURA. ARCHIVO GENERAL DE LA NACIÓN. La Provincia Oriental a principios de 1825 vista por John Hall. Montevideo: Monteverde, 1995. La edición incluye una copia facsimilar del original manuscrito en inglés, por lo que hemos podido revisar la traducción ofrecida en la edición.

5 THE BRITISH PACKET. De Rivadavia a Rosas, I, 1826-1832. Buenos Aires: Solar/ Hachette, 1976. Recopilación, traducción, notas y prólogo de Graciela Lapido y Beatriz Spota de Lapieza Elli.

6 Agradezco a Alex Borucki la consulta realizada en "The Times Digital Archive, 17851985", buscando entre 1824 y 1830 los artículos que contuvieran las palabras "Montevideo", "Banda Oriental" y "Buenos Aires". Las citas contenidas en el texto corresponden a esta versión digital del periódico. Debo agradecer también la colaboración prestada por Inés Coira para la traducción de dichos artículos. 
tener un panorama del intercambio de noticias y opiniones sobre Montevideo y la Banda Oriental manejadas por el público británico en esos lugares.

\section{Una aproximación a los estudios sobre la "mediación británica"}

Un primer ordenamiento de los trabajos dedicados a la participación de Gran Bretaña en la independencia del Uruguay puede responder a la división entre "nacionalistas" y "unionistas" señalada por José Pedro Barrán en función de las interpretaciones dadas a las leyes aprobadas por la Sala de Representantes de la Provincia Oriental el 25 de agosto de $1825 .^{7}$

La historiografía de corte nacionalista ha destacado el protagonismo de los orientales en la fórmula independentista, descartando cualquier "plan" de Gran Bretaña para la creación artificial de un "estado-tapón". La formación del Estado Oriental era vista, entonces, como la concreción de un sentimiento nacional de larguísima data. Uno de los mayores representantes de esta postura es Pablo Blanco Acevedo, en trabajos como el informe presentado en 1922 a la Comisión de la Cámara de Representantes encargada de determinar la fecha en que debía conmemorarse el Centenario de la Independencia, o la conferencia brindada en el Instituto Histórico y Geográfico del Uruguay en 1928, en ocasión del Centenario de la Convención Preliminar de Paz. ${ }^{8}$ Luis Alberto de Herrera, por su parte, en La Misión Ponsonby. La diplomacia británica y la independencia del Uruguay, publicada en 1930, sostuvo el "decisivo influjo de Inglaterra en el desarrollo de los sucesos", pero quitó a su intervención "móviles subalternos". Para este autor, la diplomacia británica apoyó una fórmula que "ya" existía y que consideró "más viable" para obtener la paz. ${ }^{9}$ Además de su extenso

7 BARRÁN, José Pedro, La independencia y el miedo a la revolución social en 1825. Revista de la Biblioteca Nacional, Montevideo, 1986, n. 24, p. 65-77. Se trata de las leyes de independencia "del Rey de Portugal, del Emperador del Brasil y de cualquiera otro del universo" y de unión "de la Provincia Oriental del Río de la Plata", "a las demás de este nombre en el territorio de Sud América" (Armand Ugon, Cerdeiras Alonso, Arcos Ferrand, Goldaracena, op. cit., p. 7-10).

8 BLANCO ACEVEDO, Pablo. La independencia nacional (Montevideo: Biblioteca Artigas, 1975, $1^{\text {a }}$ edición en 1922) y La Mediación de Inglaterra en el Convención de Paz de 1828 ( $2^{\mathrm{a}}$ ed., Montevideo: Barreiro y Ramos, 1944).

9 FREGA, Ana; ISLAS, Ariadna; REALI, Laura. Confrontando héroes. Una aproximación a las lecturas político-partidarias sobre la independencia del Uruguay (1828). In: Anais [recurso eletrônico]/2. Jornadas de História Regional Comparada, 1. Jornadas de Economia Regional Comparada, Porto Alegre: PUCRS, 2005. Las citas pertenecen a HERRERA, Luis A. de. La Misión Ponsonby. Buenos Aires: Eudeba, 1974, t. 1, p. 76-79. 
análisis, Herrera incluyó un segundo tomo con la traducción de los legajos copiados en los archivos de Londres, el que ha servido de base a nuevas investigaciones. ${ }^{10}$

Dentro de los planteos "unionistas" puede ubicarse la corriente "revisionista", que postula el carácter "artificial" de la solución propuesta y cuestiona los intereses "rapaces" de la potencia mediadora, aliada con las oligarquías portuarias de la región. ${ }^{11}$ Vivián Trías, en Las montoneras y el Imperio Británico, obra publicada en 1961, destacó que la política de Lord Ponsonby "consistió en destruir la visión artiguista de una gran Confederación de pueblos en el Río de la Plata". ${ }^{12}$ Alberto Methol Ferré, en su ensayo titulado El Uruguay como problema, cuya primera edición es de 1967, exponía el "trauma del nacimiento uruguayo". En su opinión, "habíamos sido Banda Oriental y Provincia Cisplatina, dos posibilidades que nos eran esenciales desde el origen". Pero ninguna de ellas se había concretado: "El Uruguay no es hijo de la frontera sino del mar, y el mar era inglés". ${ }^{13}$

Otros enfoques han enmarcado la negociación llevada adelante por Lord Ponsonby en la política exterior británica respecto a los países europeos y a las relaciones con las nacientes repúblicas americanas. En la introducción a la selección de documentos del Foreign Office publicada bajo el título Britain and the independence of Latin America, 1812-1830, Charles K. Webster cuestionaba las acusaciones del cónsul norteamericano sobre los intereses particulares de Gran Bretaña en la solución independentista, aseverando que la política británica se basaba "en una sabia concepción de los intereses de todas las partes en litigio". ${ }^{14} \mathrm{~A}$ conclusiones diferentes arribó H. S. Ferns, en su obra Britain and Argentina in the Nineteenth Century aparecida en 1960. Manejando también la documentación existente en los archivos británicos, este

10 Herrera, op. cit., t. 2. Pocos años más tarde publicó un nuevo trabajo y aporte documental titulado "La paz de 1828". Revista del Instituto Histórico y Geográfico del Uruguay, Montevideo, t. XIII, 1937, p. 3-106; t. XIV, 1938, p. 3-76 y t. XV, 1939, p. 55-98.

11 Sobre esta corriente en el Río de la Plata puede consultarse de HALPERIN, Tulio. El revisionismo histórico argentino. Buenos Aires: Fondo de Cultura Económica, 1970.

12 TRÍAS, Vivián. Las montoneras y el Imperio Británico. Montevideo: Ediciones Uruguay, 1961, p. 58.

13 METHOL FERRÉ, Alberto. El Uruguay como problema en la cuenca del Plata entre Argentina y Brasil. Montevideo: Diálogo, 1967, p. 20-21.

14 WEBSTER, Charles K. Gran Bretaña y la independencia de América Latina, 1812-1830. Buenos Aires: Guillermo Kraft Ltda., 1944, p. 103-104. La edición en inglés es de 1938. 
historiador sostuvo que, habida cuenta de los tratados y regulaciones comerciales existentes con las Provincias Argentinas y el Brasil, el "único interés" de Gran Bretaña en 1825 era la paz. Asimismo, marcó que aún sin poder ofrecer "ninguna declaración precisa", "Canning y sus colegas alentaban la esperanza de ver un Estadotapón independiente tanto de la Argentina como de Brasil". ${ }^{15}$

En una obra finalizada hacia 1975, Carlos Real de Azúa realizó un exhaustivo análisis de lo que consideró "los elementos esenciales de la mediación desde la perspectiva de la independencia del Uruguay", en un capítulo titulado sugestivamente "La espada de Brenno". ${ }^{16}$ A través de una lectura detenida de la producción bibliográfica y las fuentes éditas disponibles, el ensayo recorre los principales argumentos manejados en la negociación, tales como los intereses comerciales, la apertura de los ríos a la libre navegación, las ventajas derivadas de que más de un estado controlara las riberas del Río de la Plata, los proyectos para dar a Montevideo el estatuto de "puerto libre" al estilo de las ciudades hanseáticas, la imposibilidad de obtener la paz por otros conductos, los beneficios que obtendrían tanto las Provincias Unidas como el Brasil, y el papel de los "estados tapones" en el mantenimiento del orden social y el equilibrio mundial. Al dejar de lado la consideración "nacionalista", o "americanista", ya fuera respecto al futuro Estado Oriental del Uruguay o a la "patria grande", el enfoque de Real de Azúa brinda un camino alternativo a la secuencia lineal entre "conciencia nacional" y formación de un Estado. Desde su perspectiva, y dada la "extremada variabilidad" de la coyuntura, era "perfectamente factible que un grupo social fuera enteramente consciente de sus fines pero no viera con la misma claridad el modo de promoverlos, divergiendo entonces sus integrantes en el modo de hacerlo" o "cambiando unánimemente de línea al tenor de los acontecimientos". ${ }^{17}$

En 1985, José Pedro Barrán reclamó abordar el tema de la independencia del Uruguay con un enfoque que diera cuenta del "contexto social de lo político". ${ }^{18}$ Para ello, por ejemplo, recurría a

15 FERNS, H. S. Gran Bretaña y Argentina en el siglo XIX. $4^{\mathrm{a}}$ reimpr. Buenos Aires: Solar, 1984, p. 167.

16 Real de Azúa, op. cit., p. 354-391. El título recuerda el episodio de la capitulación de la antigua Roma ante los galos comandados por Brenno a quien se le adjudica la frase: "Vae victis" (Ay de los vencidos).

17 Real de Azúa, op. cit., p. 441.

18 Barrán, loc. cit., p. 73-76. El artículo fue publicado por primera vez en el Semanario Brecha: Montevideo, 11 de octubre de 1985. 
la caracterización de posiciones o "partidos" realizada por el cónsul británico en Montevideo a comienzos de $1825 .{ }^{19}$ Se identificaban allí cuatro grupos con matices en su interior: los "negativos" entre los que había españoles y criollos, "indiferentes respecto a quién gobierna, siempre que el gobierno sea bueno y ellos posean seguridad para sus personas y sus propiedades"; los "realistas", compuesto de "viejos españoles" que si bien tenían "prejuicios nacionales contra los brasileños", reconocían la "tranquilidad, moderación y seguridad" de que disfrutaban con ellos; los "imperialistas", integrado no solamente por luso-brasileños, sino por propietarios de tierras y ganado entre los que se contaban "criollos y viejos españoles con las mayores propiedades y riquezas del país"; y los "patriotas", "unidos en su oposición al Brasil", pero con discrepancias "en todos los otros puntos". En este "partido" el cónsul establecía una clara distinción entre "la mayoría", "partidarios de Artigas y sus oficiales, cuyo sistema [era] la total independencia de todos los otros países, la destrucción o división de rango y propiedad, y la igualdad basada en hacer a todos igualmente pobres", y lo que consideraba "la mejor clase de patriotas", "habitantes de las ciudades", "quienes se inclinan a unirse a la federación de Buenos Ayres". De su análisis resulta claro que las "unanimidades" postuladas por "nacionalistas" o "unionistas" deben abrir paso al reconocimiento de la disparidad de intereses aún entre los potenciales aliados contra el dominio brasileño, para quienes el pasado inmediato - léase la revolución radical postulada por el artiguismo - condicionaba los caminos a seguir.

El presente artículo se inscribe en esta perspectiva de análisis, enfocando la formación de una unidad política independiente en

19 Se trata del informe de Thomas S. Hood a George Canning fechado en Montevideo el 31 de enero de 1825, ubicado en Public Record Office/Foreign Office Papers, 51/ 1, p. 156-179. Este informe había sido publicado con anterioridad a su inclusión en Barrán, Frega, Nicoliello, op. cit., p. 61-77. En inglés: HUMPHREYS, R. A. British consular reports on the trade and politics of Latin America, 1824-1826. Londres: Offices of the Royal Historical Society, 1940, p. 68-89. En español: Informes de los Cónsules Británicos al Foreign Office. Revista Nacional: Ministerio de Instrucción Pública, julio 1941, año IV, n. 43, p. 136-155; y BARRIOS PINTOS, Aníbal. Cronistas de la Tierra Purpúrea. Montevideo: Ediciones de la Banda Oriental, 1968, p. 54-74. Pablo Blanco Acevedo hace referencia a dicho informe pero no indica la fuente, limitándose a señalar que se trata de un "estudio sobre la nacionalidad uruguaya" realizado por Arnold Wright "de acuerdo con los reports de los Cónsules ingleses en Montevideo hasta 1830, existentes en el Foreing Office de Londres." (Blanco Acevedo, La independencia..., p. 58 y 132-133). 
los territorios al norte del Río de la Plata y al este del río Uruguay como uno de los resultados históricamente posibles, en una coyuntura regional en que se estaban desarrollando otros procesos de construcción estatal y en la que países como Gran Bretaña, Francia y Estados Unidos, entre otros, estaban librando una batalla por el mejor acceso a estos nuevos mercados.

\section{La Ilegada del cónsul británico a Montevideo}

Thomas Samuel Hood llegó al Río de la Plata a comienzos de 1824, en la misma embarcación que los cónsules destinados a Buenos Aires, Chile y Perú. ${ }^{20}$ Si bien se le negó la posición de Cónsul General que tenían los otros, alegando "el estado actual de los partidos en pugna en Monte Video y en vista a la incertidumbre respecto a la forma de gobierno que finalmente se establecerá ahí", este funcionario británico debía mantener fluidas comunicaciones con los cónsules "tanto al Norte como al Sud de Monte Video" y prestar especial atención a los oficios provenientes del consulado en Buenos Aires. ${ }^{21}$ Iniciada la mediación de Gran Bretaña para poner fin a la guerra entre Brasil y las Provincias Unidas, Hood recibió órdenes de mantener informados de los acontecimientos de la región a los ministros de Su Majestad Lord Ponsonby y Robert Gordon, ubicados en Buenos Aires y Río de Janeiro y seguir las órdenes que estos pudieran darle. ${ }^{22}$ Tras la finalización de la guerra y la formación de un estado independiente en la Provincia Oriental/Cisplatina, fue elevado a Cónsul General en 1830.

El arribo a la capital de la Provincia Cisplatina se produjo poco después de que concluyera el diferendo entre las tropas portuguesas comandadas por Alvaro da Costa y los partidarios de la independencia de Brasil, encabezados por Carlos Federico Lecor. ${ }^{23}$ Concluía de esa manera una situación que había afectado

20 Humphreys, op. cit., p. xi. La embarcación partió el 6 de enero de 1824 y llegó al Río de la Plata el 22 de marzo de ese año. Según este autor, Hood había servido como sobrecargo de la Marina y en 1817 como asistente del auditor de guerra en las Indias Orientales.

21 Webster, op. cit., p. 150-151. Comunicación de Canning a Hood del 15 de diciembre de 1823.

22 Barrán, Frega, Nicoliello, op. cit., p. 97. John Bidwell a Hood, Ministerio de Asuntos Extranjeros en Londres, 20 de setiembre de 1826.

23 El reingreso de las tropas de Lecor a Montevideo se produjo el 27 de febrero de 1824 (PIVEL DEVOTO, Juan E. Uruguay independiente. In: BALLESTEROS BERETTA, Antonio (dir.). Historia de América y de los pueblos americanos. Barcelona: Salvat, 1949 , p. 451. 
un flujo mercantil en extremo sensible a las variaciones políticas. En uno de sus primeros informes, Hood dio cuenta de los efectos de las "nuevas escenas de anarquía y confusión" que habían acompañado la división de las tropas de ocupación, en momentos en que, por el contrario, "los partidos políticos en la Provincia de Buenos Ayres se consolidaban". Afirmaba que en ese contexto los ingresos de la aduana montevideana habían caído a un $40 \%$ del promedio anual registrado en 1820, 1821 y 1822. ${ }^{24}$

En el ambiente político montevideano, tras ese último enfrentamiento, se apreciaba una profundización de las tensiones entre los distintos "partidos". James Weddel, quien estuvo en Montevideo hacia abril de 1824, dio cuenta de la pelea que se armó en ocasión de una cena organizada para la "celebración del tranquilo establecimiento del nuevo gobierno", cuando uno de los comensales propuso un brindis en honor a Fernando VII. Estaban presentes unas 60 personas entre "patriotas españoles", algunos americanos, franceses, portugueses e ingleses. En su opinión, "era evidente que este grupo estaba muy dividido en política; todos posiblemente eran patriotas pero cada uno a su manera", lo que explicaba por "la diversidad de intereses, junto con el cambio frecuente del sentimiento político que produce un cambio de gobierno". ${ }^{25}$

La presencia de un agente británico generó expectativas en torno al futuro político del territorio. A un mes de estar allí, Hood ya había recibido dos solicitudes para que su gobierno colaborara para poner fin a la dominación brasileña, ya fuera a cambio de recibir ventajas comerciales o disponiendo que "la Banda Oriental pasara a ser una Colonia de Gran Bretaña". En su informe, Hood relataba que le habían explicitado las razones que los alejaban de Brasil o del gobierno de Buenos Aires, para finalmente manifestarle que "lo más cercano a ser independientes por sí mismos, [era]

24 Barrán, Frega, Nicoliello, op. cit., p. 53-58. Hood a Canning, 15 de agosto de 1824. Ver también Humphreys, op. cit., p. 63-67; Informes de los cónsules..., loc. cit., p. 131-155; y Barrios Pintos, op. cit., p. 48-53. Según Hood, en los años 1820, 1821 y 1822 el promedio anual de los ingresos aduaneros se ubicó en el millón de dólares, mientras que en 1824 se recaudaban unos 34.000 dólares por mes y "más bien en vías de disminuir".

25 Traducción de un fragmento de A voyage towards the South Pole, de James Weddel, incluido como Apéndice III del artículo de REAL DE AZÚA, Carlos. Un testigo inglés de la Cisplatina: L. Boutcher Halloran. Revista Histórica, Montevideo: Museo Histórico Nacional, t. XXXIII, n. 97-99. diciembre 1962, p. 205. Weddel llegó a Montevideo el 6 de abril de 1824 y permaneció aproximadamente un mes. 
pertenecer a un Estado Poderoso y Libre". ${ }^{26}$ Ahora bien, la interpretación de este episodio no puede reducirse a una "prueba" de la vocación "nacionalista" de los orientales. ${ }^{27}$ No se encuentran en ese texto manifestaciones en tal sentido, sino más bien el interés de los sectores económicamente poderosos de obtener condiciones más favorables para el desarrollo de sus actividades. Las visitas al funcionario británico fueron realizadas por un "Caballero español", "delegado por los habitantes importantes de Monte Video y sus inmediaciones", y por "dos Caballeros" "de la mayor respetabilidad", que presentaron una argumentación centrada principalmente en el control del comercio y del territorio. Unos meses más tarde, en diciembre de 1824, el agente británico daba cuenta de los éxitos del "criterioso y conciliador" gobierno de Lecor, que había ido eliminando los "prejuicios" de los españoles peninsulares ("viejos españoles") y los criollos hacia los portugueses y los brasileños, ganando adeptos "particularmente entre los hombres de capital y comercio". ${ }^{28}$ En el mismo informe, el cónsul ubicaba a los "descontentos", cuyo número era todavía "considerable", "entre los hombres desprovistos de propiedad y de capital", y que poco tiempo después serían la base del levantamiento armado contra los brasileños.

En la caracterización de los "partidos" a comienzos de 1825, los "ansiosos por conseguir la ocupación británica" se hallaban, según Hood, en el variado grupo de los "negativos", siendo "unos pocos que han sido admiradores de la disciplina británica, mientras este lugar estuvo en posesión del General Sir Samuel Auchmuty". ${ }^{29}$ Sobre este aspecto, el informante del cónsul abundó en detalles. Se trataba de John Hall, comerciante, propietario de un saladero y dueño de una casa quinta en las inmediaciones de Tres Cruces (extramuros de Montevideo), quien le proporcionó a Hood una descripción sobre el estado general de la provincia y su posición en la región que sirvió de base para el detallado informe que el funcionario elevó a sus superiores. En su comunicación, Hall indicó

26 Barrán, Frega, Nicoliello, op. cit., p. 51-52. Hood a Canning, 22 de abril de 1824. Ver también Webster, op. cit., p. 154-156.

27 Pablo Blanco Acevedo lo interpreta de esa manera. Cabe aclarar que ubica erróneamente este documento en el año 1823, en el marco de la división de las tropas de ocupación y los intentos de organización de un movimiento de liberación del dominio luso-brasileño (Blanco Acevedo, La independencia..., p. 57-58).

28 Barrán, Frega, Nicoliello, op. cit., p. 59. Hood a Joseph Planta, 28 de diciembre de 1824.

29 Ibid., p. 69. Informe fechado el 31 de enero de 1825. Se refiere a la ocupación de Montevideo entre febrero y setiembre de 1807. 
otros partidarios del dominio "de algún gobierno europeo rico y poderoso que pudiera defenderlos y activar su agricultura y comercio". Se trataba de algunos criollos "que odian a los realistas brasileños y a los porteños", pero temen "el retorno de las violencias y desórdenes" de la "Patria", y de algunos portugueses europeos, desconformes con la "pobreza del gobierno brasileño". ${ }^{30}$ No era esta una posición novedosa en esos grupos sociales, y la presencia de un funcionario británico en la plaza abría una nueva oportunidad para negociar una alianza que pudiera brindarles seguridad en el desarrollo de sus negocios y el control de los recursos de la provincia.

\section{El papel de Montevideo en la región}

La idea de conformar un estado independiente en la ribera norte del Río de la Plata con la finalidad de garantizar la actividad mercantil no era nueva. Tal había sido, por ejemplo, la postura sostenida por el Comandante de la Estación Naval británica en 1819. Los comerciantes padecían las disposiciones de ambos bandos, que ya fuera urgidos por la necesidad de recursos, o con el interés de aislar al enemigo, tomaban medidas como la suba de los derechos de reembarco de las mercaderías británicas dispuesta por el gobierno bonaerense, o como el aumento "sorpresivo" de los derechos aduaneros a casi un 25\% fijada por Lecor en Montevideo, junto a la exclusividad del comercio costero para los navíos de bandera portuguesa y la amenaza de bloquear el río Uruguay y no permitir que embarcaciones extranjeras entraran en Maldonado o Colonia. Mientras continuara la guerra - afirmaba el Comodoro William Bowles - cualquier método para conseguir dinero sería llevado adelante en detrimento de los intereses comerciales británicos. Por ese motivo, era de la opinión de que resultaría una "gran ventaja para los intereses británicos", un "arreglo final" mediante el cual Montevideo "quedara enteramente independiente de Buenos Ayres y en la posición de poder adoptar un sistema comercial tan estable y liberal como para animar a los extranjeros a constituir en la ribera izquierda del Plata su principal establecimiento". ${ }^{31}$

30 Hall, op. cit., p. 13.

31 GRAHAM, Gerald S., HUMPHREYS, R.A. (ed.). The Navy and South America, 1807-1823. Correspondence of the Commanders-in-Chief on the South American Station. Londres: The Navy Records Society, 1962, p. 273-277. Despacho de Bowles a Croker, a bordo del Amphion, Buenos Aires, 31 de agosto de 1819. Esta salida también había sido planteada en esos años por la cancillería británica (Real de Azúa, Los orígenes..., p. 388, nota 32). 
A la llegada del cónsul a Montevideo, como se vio, el comercio estaba muy deprimido. A la poca población, su empobrecimiento y "la falta de ganado o productos para la exportación", se sumaban la diferencia de tarifas en favor de Buenos Aires y su liderazgo en el proceso de reconstitución de las Provincias Unidas. Por tanto, como informaba Hood a comienzos de 1825, mientras no hubiera "con qué pagar nuestras importaciones, posiblemente el comercio no pueda aumentar en forma muy considerable", "a menos que sea por consignaciones, para lo que el puerto está peculiarmente adaptado por naturaleza". ${ }^{32} \mathrm{El}$ progreso de una ciudad puerto se veía en contradicción con la otra. Ambos lugares se disputaban cumplir la función de depósito y reexpedición del comercio de importación y exportación en la región. Con ese enfoque contestó John Hall la consulta sobre un eventual envío de tropas para desalojar a los brasileños de la Provincia Oriental, que pudiera disponer el gobierno de Buenos Aires. Su respuesta deja traslucir el "antiporteñismo" existente en la mayoría de los "partidos" o grupos de opinión en Montevideo. Luego de descartar que el principal interés fuera disponer de los recursos de la Provincia, indicaba dos motivos para "que el gobierno de Buenos Aires des[eara] obtener esta provincia". El primero aludía directamente a la llamada "lucha de puertos", en tanto la posesión de Montevideo evitaría que pudiera volver a "despojar" al puerto de Buenos Aires de su comercio. El segundo tenía que ver con la formación de la República de las Provincias Unidas - controlar las dos márgenes del Río de la Plata permitiría al gobierno de la capital ejercer una "mayor influencia sobre las provincias del interior y obligarlas a doblegarse a sus planes de dominación" - y ponía en riesgo la "libre navegación de los ríos". Decía Hall que si el gobierno bonaerense triunfaba en su propósito de ocupar Montevideo, "también sería capaz de imponer a las naciones extranjeras los términos bajo los cuales podrían navegar este río", pudiendo interrumpir incluso la conexión de Paraguay con el Viejo Mundo o retardar "la población de las provincias del Brasil entre los ríos Uruguay, Paraná y Paraguay." Y advertía: "Por supuesto que las naciones europeas no pueden coincidir con Buenos Aires en esto". ${ }^{33}$

32 Barrán, Frega, Nicoliello, op. cit., p. 72.

33 Hall, op. cit., p. 23. 
No se trata en este artículo de indagar hasta qué punto eran estos los propósitos que perseguía el gobierno de Buenos Aires - o por lo menos alguno de los partidos allí existentes - respecto al futuro de la ribera septentrional del Río de la Plata. Interesa observar las coincidencias de los propietarios nativos o extranjeros residentes en Montevideo, en cuanto al papel que la ciudad-puerto debía desempeñar en la región. A diferencia de la formulación de Pablo Blanco Acevedo, que ligaba la disputa portuaria al sentimiento de nacionalidad, lo que observamos es una postura similar sobre este punto entre quienes tenían su giro principal en Montevideo, en forma independiente a que aspiraran a formar un nuevo estado, volver a integrar la monarquía española, ponerse bajo la tutela de algún gobierno "rico y poderoso" o conservar su calidad de extranjeros. En los "viejos españoles", por ejemplo, es interesante observar una línea de continuidad entre planteos de fines del siglo XVIII destinados a "ensanchar" la jurisdicción de la gobernación de Montevideo, su transformación en intendencia y la erección de un consulado, y las posiciones sostenidas durante las guerras de independencia y luego de la ocupación lusobrasileña. El control del comercio regional y de ultramar a través del puerto de Montevideo y el acceso a un territorio mayor, rico para la explotación ganadera, guiaron la política de alianzas de este grupo. Como subrayaba Felipe Contucci desde la frontera con el Brasil al comerciante español Mateo Magariños a fines de 1820, se trataba de "aumentar los intereses de la Nacion, y obstruir los progresos de nuestros vecinos". ${ }^{34}$ La experiencia inmediata mostraba cuánto había progresado el comercio o cuánto había decaído según los movimientos políticos en la región. En su ya citado informe de comienzos de 1825, Hood presentó los contrastes entre el período de "agitación interna" en Buenos Aires, cuando muchos comerciantes con sus capitales "se refugiaron bajo la bandera de Portugal" y en Montevideo se "abrió un vasto comercio con las Provincias en el Entre Ríos", con lo sucedido luego de que cesaron "las pasiones turbulentas" en Buenos Aires y su gobierno bajó del 33\% al 15\% los derechos de introducción de manufacturas y fijó un $2 \%$ sobre el tránsito de las mismas, consiguiendo recuperar el "vasto comercio con las provincias de arriba". ${ }^{35}$ Tras la ruptura

34 Archivo General de la Nación (Montevideo), Fondo Archivos Particulares, Caja 105Carpeta 1, fs. 47-50v. Guardia del Cerrito, noviembre de 1820.

35 Barrán, Frega, Nicoliello, op. cit., p. 55. 
del orden colonial y el planteo de la soberanía de los pueblos que dio lugar a la constitución de nuevos sujetos soberanos en el Río de la Plata, se abrió paso también la exigencia del comercio libre - sin duda fomentada por europeos y estadounidenses - en los puertos fluviales del Paraná y el Uruguay. La posibilidad de contar con Buenos Aires o Montevideo como puertas de entrada a la región habilitó una interesante geometría de alianzas, que acompañó los procesos de construcción y afirmación estatal hasta avanzado el siglo XIX.

Concluida la paz entre las Provincias Unidas y Brasil, una carta desde Montevideo expresó las esperanzas de recuperar posiciones frente a Buenos Aires como efecto de una rebaja de los derechos de importación, exportación, tránsito y re-exportación de mercaderías. Según el corresponsal, con ello el puerto de Montevideo pasaría a ser el depósito general de los productos importados de Europa y Estados Unidos con destino a la República Argentina, Bolivia, Chile y Perú. Reafirmando la superioridad de esta plaza "por la posición, extensión y seguridad de su puerto", se agregaba que aún a pesar de las disensiones con Buenos Aires, los canales de los ríos Paraná y Uruguay siempre serían accesibles a embarcaciones pequeñas para la introducción de mercaderías a las "nuevas repúblicas y el Paraguay". ${ }^{36}$

\section{Los comerciantes británicos en Montevideo y la guerra}

Según la información proporcionada por el cónsul, los establecimientos británicos apenas pasarían de una decena, estando el comercio de la plaza controlado por los luso-brasileños. La llegada del agente británico significó para los súbditos de ese país la posibilidad de presentarse a las autoridades con mayor fuerza, pero como se verá a continuación, no siempre con resultado exitoso. Coincidían con sus coterráneos de la otra ribera del Plata en la exigencia a su gobierno de las medidas necesarias para su protección, pero su giro era objetivamente menor que el de Buenos Aires. No contaban con un tratado de amistad, navegación y comercio como el suscrito entre Gran Bretaña y la República de las Provincias Unidas, que completó el proceso de reconocimiento de $\mathrm{su}$ independencia $\mathrm{y}$, en consecuencia, tampoco con un encargado

36 The Times, Londres, 21 de noviembre de 1829, p. 2. Carta fechada el 15 de julio y publicada originalmente en Journal du Commerce. 
de asuntos extranjeros. ${ }^{37}$ En lo que refiere a la variedad y volumen de los negocios, al ser una provincia de un imperio y no la capital de un estado, estaban más acotados en el espacio y en el tipo de operaciones. Un ejemplo del predominio de sus pares de Buenos Aires es que, ante los distintos rumores sobre una paz inminente, las mercaderías embarcadas tenían como destino final la capital de las Provincias Unidas, indicándose que solamente en caso de persistir el bloqueo fueran depositadas en Montevideo. ${ }^{38}$

El cónsul procuró mantener las mejores relaciones con las autoridades en Montevideo, sobre todo después del inicio de las operaciones militares de los patriotas. Solicitó al Comandante de la flota británica una embarcación de guerra para la protección general del comercio y del movimiento mercantil en el Río de la Plata y alertó a sus compatriotas sobre "los efectos perjudiciales" de cualquier desvío "de la estricta neutralidad". ${ }^{39}$ Los informes de Hood dan cuenta de diversos reclamos de los comerciantes británicos, en algunos casos vinculados a la posición de Montevideo en el Imperio brasileño, en otros derivados de su condición de extranjeros y, finalmente, los producidos a raíz de los perjuicios provocados por la prolongación de la guerra. En diciembre de 1826, por ejemplo, los comerciantes británicos residentes en Montevideo elevaron al cónsul un pedido para que realizara una protesta formal contra el 9\% más de derechos de importación que debían pagar las manufacturas británicas en ese puerto, en comparación con los demás de Brasil. La situación se había vuelto más injusta, decían, desde el momento en que la firma de un tratado entre Brasil y Francia eximía de tal recarga a los productos de ese origen. ${ }^{40}$ Además, esta situación los ponía en condiciones desfavorables frente a los comerciantes nativos,

37 A ese rango fue elevado el cónsul general Woodbine Parish en mayo de 1825 luego de la ratificación del tratado citado (The Times, 18 de octubre de 1825, p. 2 BuenosAyres Papers. Transcribe artículo de El Argos, Buenos Aires, 23 de julio).

38 Barrán, Frega, Nicoliello, op. cit., p. 118.

39 Barrán, Frega, Nicoliello, op. cit., p. 83-86. Hood a Canning, 10 de mayo de 1825. En 1827, en ocasión de rendir homenaje al nuevo presidente de la Provincia Cisplatina, el Dr. Tomás García de Zúñiga, Hood recordó que Lecor había fomentado su comercio tanto como le había sido posible (Semanario Mercantil de Montevideo, n. 62, p. 266-267. Alocución).

40 Barrán, Frega, Nicoliello, op. cit., p. 109-110. Petitorio firmado por John Gowland, William Wilson, Stanley y Black Co., John Hall Co., John Hague, Charles M. Kinnon, John Lewis Darby, James Noble, Bertram Armstrong Co., John MacFarlane y James Kendall, Montevideo, 26 de diciembre de 1826. Las manufacturas pagaban un 15\% de derechos de introducción en los puertos de Brasil y un 24\% en Montevideo. 
que veían la posibilidad de adquirir directamente las mercaderías en Río de Janeiro, incluso a comerciantes británicos residentes allí. $^{41}$

La situación periférica de la Provincia Cisplatina en el Imperio, tanto en lo político como en lo económico, así como las urgencias fiscales provocadas por la guerra, afectaban a los comerciantes británicos residentes en Montevideo, quienes debían elevar sus representaciones ante el ministro de su país en Río de Janeiro. A su vez, la interrupción de las comunicaciones con los establecimientos mercantiles británicos en Buenos Aires derivada del bloqueo dispuesto por Brasil, dejó en evidencia que la mayoría de las casas comerciales británicas en Montevideo eran sucursales de las de aquella ciudad y que la introducción de esos productos en el mercado montevideano causaría efectos "ruinosos" dado que "inundaría la plaza".42 Las opiniones contenidas en The British Packet respecto al bloqueo que la flota brasileña imponía al puerto de Buenos Aires expresan, en forma indirecta, su aspiración a controlar el comercio del Río de la Plata. En un artículo donde se preguntaban hasta cuándo las naciones extranjeras iba a seguir tolerando el bloqueo, llamaban a la República a no aceptar "ser un mero apéndice del imperio brasileño, cuyos navíos, amos de Montevideo, pueden interceptar a voluntad la navegación del río y cuyas bayonetas brillan desde Maldonado hasta Las Vacas". ${ }^{43}$ En este como en otros artículos se sostuvo la conveniencia de que el gobierno de Buenos Aires controlara las dos riberas del Río de la Plata. Estos indicios nos permiten sostener que los súbditos británicos residentes en el Río de la Plata no tenían una posición homogénea sobre el destino de Montevideo, y que en algunos casos ésta era discrepante incluso con la llevada adelante por los representantes de la corona.

Las "arbitrariedades" del gobierno brasileño alcanzaron otros aspectos. Hood denunció ante el enviado extraordinario de la corona británica en Río de Janeiro, Robert Gordon, el tratamiento desigual que recibían los comerciantes de su nación, obligados a

41 Luego de las gestiones infructuosas ante las autoridades de la provincia, Hood se dirigió a Robert Gordon, enviado extraordinario del gobierno británico en Río de Janeiro y dio cuenta a sus superiores en el Ministerio de Asuntos Extranjeros. Véase: Barrán, Frega, Nicoliello, op. cit., p. 113-115. La nota a Gordon está fechada el 18 de febrero de 1827 y a John Bidwell el 10 de marzo de ese año.

42 Barrán, Frega, Nicoliello, op. cit., p. 91 y 117-119. Notas de Hood a Canning y a Gordon de fechas 15 de junio de 1826 y 18 de mayo de 1827.

43 The British Packet, op. cit., p. 136-138 (artículo fechado el 1 de setiembre de 1827). 
desembarcar sus cargamentos y depositarlos en la Aduana transcurridos los quince días hábiles del arribo al puerto de Montevideo, mientras que la disposición no se aplicaba a los buques de bandera norteamericana o francesa. ${ }^{44}$ Las rivalidades mercantiles entre estas naciones se expresaron de diversa forma, siendo una de ellas la posición tomada frente al bloqueo brasileño al puerto de Buenos Aires. El encargado de negocios de Estados Unidos en Buenos Aires, John Murray Forbes informó a sus superiores las protestas formuladas por él y por el almirante francés, quien habría manifestado que no reconocería otro bloqueo que no fuera de facto, es decir, con una fuerza naval que pudiera hacerlo efectivo. ${ }^{45} \mathrm{~A}$ su vez, una embarcación que había partido de Río de Janeiro el 30 de junio de 1826 mencionaba el desplazamiento de navíos de guerra estadounidenses con rumbo a Montevideo, con el cometido de no permitir a la escuadra brasileña la interrupción del tránsito a y desde Buenos Aires a las embarcaciones de su bandera. ${ }^{46}$ Thomas Hood debió intervenir contra el apresamiento de embarcaciones británicas, así como ante las trabas impuestas a J. A. B. Beaumont para que el contingente de unos doscientos inmigrantes que traía pudiera llegar al Entre Ríos. ${ }^{47}$

Las autoridades cisplatinas impusieron a los capitanes de las embarcaciones extranjeras la presentación de una fianza "buena y aprobada" a efectos de garantizar que no violaran el bloqueo impuesto al puerto de Buenos Aires. En su nota al Presidente de la Provincia Cisplatina, Dr. Tomás García de Zúñiga, Hood solicitó la suspensión de esa orden hasta la resolución definitiva del Emperador y propuso que, como medida paliativa, se aceptaran las garantías ofrecidas por los comerciantes británicos residentes en la plaza, "en lugar de terratenientes locales", "cuya firma solo

44 Barrán, Frega, Nicoliello, op. cit., p. 117-119. Hood a Gordon, 18 de mayo de 1827.

45 FORBES, John Murray. Once años en Buenos Aires. 1820.1831. Buenos Aires: Emecé, 1956, p. 430-431. Véase también The Times, Londres, 6 de junio de 1826, p. 2.

46 The Times, Londres, 4 de setiembre de 1826, p. 2 (Brazil and Buenos-Ayres). Allí se informaba también sobre la "obstinación" del Emperador en favor de continuar la guerra y las negociaciones sobre la sucesión del trono de Portugal. Esas embarcaciones habrían llegado a Montevideo en la primera quincena de julio (Forbes, op. cit., p. 439-440).

47 Beaumont llegó a Montevideo a mediados de 1826. Además de la asistencia del cónsul británico, destacó especialmente el apoyo recibido del importante comerciante español Francisco Juanicó (BEAUMONT, J. A. B. Travels in Buenos Ayres, and the adjacent provinces of the Rio de la Plata. London: James Ridgway, MDCCCXXVIII, p. 1-9. Versión electrónica: http://books.google.com.uy/books). 
puede procurarse por un fuerte pago". ${ }^{48}$ A comienzos de 1828, Hood debió protestar enérgicamente por la disposición de las autoridades cisplatinas de quitar el timón a una embarcación británica acusada de pretender dirigirse a Buenos Aires. ${ }^{49} \mathrm{Si}$ bien el bloqueo podía no ser muy estricto y para varios países no lo fue, lo cierto es que a comienzos de 1828 se intensificaron los reclamos para que Gran Bretaña se decidiera finalmente por no reconocerlo. Cabe señalar que Carlos Real de Azúa, en su interpretación de la mediación británica, sugiere que la política del bloqueo estricto, es decir, que en forma independiente a la fuerza efectiva de la escuadra que había dispuesto el bloqueo de un puerto, no se pudieran asegurar embarcaciones o cargas con ese destino, fue seguida por Gran Bretaña para mantener una cierta paridad de ambos contrincantes e incidir desde una posición de mayor fuerza en la fórmula de la paz. ${ }^{50}$

Concretada la paz, las noticias llegadas a Londres desde Montevideo eran exageradamente auspiciosas. Mientras las Provincias Unidas y el Imperio habían cargado con los costos de la guerra, la Banda Oriental se habría beneficiado. Se decía que los brasileños habían mejorado sustancialmente la ciudad, que los "saqueos de las provincias del sur de Brasil por los Gauchos" habían permitido recuperar el stock ganadero y que Montevideo estaba recibiendo muchos inmigrantes provenientes de Buenos Aires. ${ }^{51}$ Pero ello, aún de ser cierto, no parecía ajustarse a la situación de los comerciantes británicos en Montevideo quienes, con la formación del nuevo estado, temían perder las garantías que los tratados entre Portugal, Brasil y Gran Bretaña brindaban a sus personas y propiedades. En ese marco, William Wilson, en su calidad de presidente de la Asociación de Comerciantes de Liverpool, Brasil y Río de la Plata, elevó al Ministro de Asuntos Extranjeros, Conde de Aberdeen, un petitorio para que fuera "inmediatamente registrado" un tratado con el nuevo estado independiente "para la mejor seguridad y protección de los

48 Barrán, Frega, Nicoliello, op. cit., p. 131-132. Nota fechada el 18 de diciembre de 1827.

49 The Times, Londres, 17 de abril de 1828, p. 2.

50 Real de Azúa, Los orígenes..., p. 422-424.

51 The Times, Londres, 7 de enero de 1830, p. 2 (las cartas estaban fechadas el 15 de octubre anterior). Más interesante que sus impresiones sobre la "prosperidad" del nuevo estado es su pronóstico acerca de quién será electo primer presidente del mismo: Fructuoso Rivera. 
residentes británicos y del comercio" ${ }^{52}$ Esa aspiración demoró una década en concretarse.

\section{El derrotero de la postura independentista}

Desde su llegada, Hood había manifestado a sus superiores una visión optimista respecto a la capacidad del gobierno brasileño para mantener la tranquilidad y ganarse el apoyo de "todos los ricos e inteligentes" de la provincia. Al referir al "partido" de "la mejor clase de Patriotas" en su informe del 31 de enero de 1825 ya citado, el agente británico había señalado que sus integrantes, ante la escasez de población y rentas y del país, habían abandonado "la idea de constituir un estado soberano" y que "por relaciones locales y familiares se inclina[ban] por la federación de Buenos Ayres". Agregaba, sin embargo, que ante la probabilidad de ir a "otra guerra de guerrillas" por la dificultad de someter a "la gente de la campaña" a esa nueva autoridad, la mayor parte de ellos se mantenía "pasiva" y en el corto plazo, una política "conciliadora" y "apaciguadora" podría llegar a asimilarlos a los brasileños. ${ }^{53}$ Es más, aún luego del inicio de las operaciones militares, el cónsul británico escribió a sus superiores que el gobierno de Lecor contaba con el apoyo de "los viejos españoles, los brasileños y las clases más altas de los criollos". El "miedo a la revolución social", al decir de Barrán, propiciaba alianzas que no tenían en cuenta los lugares de nacimiento. En la descripción del agente británico, el movimiento armado estaba encabezado por "numerosos descontentos pertenecientes a esta Provincia que habían servido bajo las órdenes de Artigas" y que tenían por "objetivo la expulsión de los brasileños y la creación de un gobierno independiente o, más bien, la supresión de todo gobierno y el establecimiento de la anarquía y la confusión" ${ }^{54}$

A casi un año de haberse votado la "reincorporación" de la Provincia Oriental a las Provincias Unidas del Río de la Plata, Hood reportó a las autoridades que desde hacía algunas semanas, entre "los más respetables e importantes hombres del partido patriota en esta ciudad y la provincia" se había planteado "la idea de organizar un partido independentista con la esperanza, en el actual

52 Barrán, Frega, Nicoliello, op. cit., p. 167. El documento no tiene fecha pero presumiblemente es de 1829.

53 Ibid., p. 68-69.

54 Ibid., p. 83-86. Hood a Canning, 10 de mayo de 1825. 
estado de cosas, de librarse de los bonaerenses y los brasileños, y establecer una República de ellos, bajo el principio de los Estados Hanseáticos". ${ }^{55}$ La novedad era, entonces, que ese partido independentista se estaba formando con miembros de "la mejor clase de patriotas". El resto del informe se centró en los argumentos que fundamentaban este cambio de opinión. Indicaba que era "bien conocido" que la unión a la "República de Buenos Aires" por medio del "partido de las armas" había sido "una medida de conveniencia" para involucrar a las Provincias Unidas en una guerra con Brasil, "con miras, en el fondo de separarse ellos mismos de Buenos Ayres una vez que los brasileños hubieran sido expulsados". Consciente de esta situación, el gobierno de las Provincias Unidas procuró debilitar el poder de los jefes locales, removiéndolos bajo distintos pretextos e incorporando las milicias orientales al ejército nacional. El descubrimiento de estas "intrigas", según Hood, habría arraigado un "sentimiento hostil a los intereses de Buenos Ayres". Ello estaría relacionado, por ejemplo, con los movimientos de Bernabé Rivera, separado del Ejército Republicano, quien había establecido un punto de reunión al norte del río Negro, siendo probable, según Hood, que contara con apoyo de grupos civiles y estuviera en conexión con Fructuoso Rivera. ${ }^{56}$ El agente británico manifestaba su escepticismo sobre el futuro de esa nueva entidad política, afirmando que si no contaba con el apoyo de "algunas naciones desinteresadas", conduciría "a una interminable anarquía y confusión y a la ruina y destrucción de la mejor parte, por lejos, de Sud América".

En diciembre de ese año, desde las páginas de la Gaceta de la Provincia Oriental, afín a la orientación "unitaria" de la Sala de Representantes, se acusó a Hood de insistir ante su gobierno y el pueblo británico "para convencerle, que los orientales quieren ser portugueses, ó en todo caso mas bien ingleses, que miembros de la confederación argentina". Indicaba que ello había provocado "una competencia sobre la cuestión de Montevideo" en los números de The Times de agosto y setiembre

55 Barrán, Frega, Nicoliello, op. cit., p. 99-100. Hood a Bidwell, 2 de octubre de 1826. Debe tenerse presente que esta postura coincide con la fórmula que el mediador británico estaba manejando como la más viable en ese momento ante el Presidente de las Provincias Unidas (Webster, op. cit., p. 213-219. Ponsonby a Canning, 2 de octubre de 1826. Véase también, Herrera, La misión..., t. 2, p. 58-64).

56 Sobre las rupturas al interior del ejército republicano y las actividades de Rivera y Lavalleja véase Real de Azúa, Los orígenes..., p. 116-129. 
de $1826 .{ }^{57}$ Si bien no encontramos en el periódico londinense ninguna comunicación del cónsul en Montevideo en esos meses, resulta de interés reseñar dos menciones a la situación en el Río de la Plata. El primer artículo refiere a las dificultades que afrontaba la negociación de Lord Ponsonby, en tanto ni Rivadavia ni el Emperador estaban dispuestos a ceder, ya fuera en un caso admitiendo la anexión a Brasil, o en otro, la independencia de Montevideo. Las razones para ello tenían que ver, de parte de las Provincias Unidas, en que "Montevideo [era] un puesto fronterizo defensivo y necesario", que en manos de los brasileños, dejaba sin protección a Buenos Aires, "capital de un estado extenso". La argumentación sobre la negativa de Pedro I se centraba en su temperamento, concluyendo el articulista que era muy improbable que el Emperador de Brasil aceptara que Montevideo se erigiera como puerto libre con la protección británica. ${ }^{58}$ Cabe aclarar que la posibilidad de la garantía británica estaba acotada exclusiva-mente a la libre navegación del Río de la Plata y no a la integridad de una nueva unidad política.

La segunda mención es una carta dirigida al director del periódico, firmada por "Un observador". 59 Sería muy interesante determinar la identidad del autor, que bien podría ser nativo o habitante del Río de la Plata. Comenzaba con una ubicación a los lectores en el vocabulario de la región, indicando que llamaría "Argentinos" a los habitantes de la República de La Plata, para distinguirlos de los habitantes de la Provincia de Montevideo, nombrada como Banda Oriental del Uruguay, los que eran conocidos como "Orientales". La nota presenta una extensa argumentación contra la propaganda que desde unos dos meses atrás - según el autor - se venía haciendo al público británico a favor de que la mejor manera de terminar la guerra era el establecimiento "de un estado independiente" en el que los orientales pasaran a ser una "comunidad", separada tanto de los argentinos como de los brasileños. En su opinión, al contrario de lo que se venía sosteniendo, la salida independentista otorgaba al Imperio de Brasil las mejores posibilidades para reconquistar ese territorio en el momento en que lo considerara más oportuno. Además, como era muy factible que cualquier decisión que afectara

57 Gaceta de la Provincia Oriental, n. 5. Canelones, 12 de diciembre de 1826 [p. 1]. INSTITUTO HISTÓRICO Y GEOGRÁFICO DEL URUGUAY. Gaceta de la Provincia Oriental. Canelones, 1826-27. Montevideo: Barreiro y Ramos, 1943. Reproducción facsimilar.

58 The Times, Londres, 17 de agosto de 1826, p. 2.

59 The Times, Londres, 26 de agosto de 1826, p. 3 ("Brazil and Buenos-Ayres. To the Editor of The Times", por An Observer. La carta está fechada el 18 de agosto). 
a la Banda Oriental arrastrara también a Entre Ríos, Corrientes y Misiones, e incluso a Paraguay, Brasil estaría en condiciones de avanzar también sobre esas otras provincias, pues "dejadas a sí mismas", serían progresivamente separadas una de la otra. El otro eje argumental aludía al carácter de la mayoría de los habitantes de esos lugares - criadores de ganado, de vida errante y aventurera, familiarizados con los peligros de la guerra - y a su posición, es decir, muchos de ellos en el ejército, con el control de la totalidad del territorio provincial a excepción de Montevideo y Colonia, capaces de mover al resto de la población tras sus acciones. Alertaba sobre los peligros que podían derivar de su adhesión a la postura de la independencia, indicando que esa anticipación de males no era más que la historia vivida desde los años 1811 y 1812 hasta el presente: "Artigas, el errado jefe de los Orientales durante esos años, envenenó las mentes de muchos de ellos con sugestiones concernientes a una forma y un modo de gobierno local para los que no estaban preparados". En su opinión, "aquel que deseara servir a los orientales" no debía dañar "los lazos de unión que han sido renovados entre ellos y sus hermanos argentinos", sino que debía promover su fortalecimiento. A pesar de esa visión prejuiciosa sobre los habitantes de la región, el autor de la nota procuraba reforzar la existencia de una "comunidad" que los abarcase a todos, afirmando: "Los orientales, así como los habitantes de Entre Ríos y las otras tres provincias, son tan argentinos como los bonaerenses, los cordobeses y los habitantes de las provincias sureñas y occidentales". El autor no parecía defender ninguna posición respecto a la futura organización de las provincias del Río de la Plata sino que, por el contrario, llamaba a no interferir en los asuntos domésticos: "ellos son los jueces más competentes para decidir si la mejor estructura es una combinación de provincias unidas o un sistema de estados federales". Estas opiniones parecen cercanas a la disyuntiva que planteara el editor de The British Packet en Buenos Aires, el sentido de que si la Provincia aceptaba la independencia, podría convertirse en "una pequeña república", pero "si desea[ba] participar en los beneficios de la seguridad y grandeza nacional, preferir[ía] convertirse en parte integrante de la República Argentina". ${ }^{60}$

60 The British Packet, op. cit., p. 52-55 (artículo fechado el 6 de enero de 1827). El artículo informaba: el gobierno de las Provincias Unidas "ha propuesto renunciar a todas sus reclamaciones de subordinación por parte de esa provincia y permitir a sus habitantes elegir su gobierno, dejándolos enteramente independientes, con la condición de que los brasileños retiren sus fuerzas y desliguen al pueblo de todas las obligaciones de obediencia que le corresponderían como parte integrante del imperio brasileño". 
En diciembre de 1826, aunque sin hacer mención al "partido independentista", el cónsul informó sobre dos circunstancias que podían favorecer una salida que no involucrara la subordinación al gobierno de Buenos Aires. Por una lado, anotó la existencia en el ejército de un "espíritu de rivalidad altamente excitado y peligroso, prevaleciente en casi todos los orientales y bonaerenses"; por otro, hizo referencia al "sentimiento de gran rencor contra los bonaerenses", provocado por un decreto de la jefatura del ejército republicano disponiendo la evacuación de la zona ubicada entre lo que llamaban "sus líneas", en las cercanías de Montevideo, y los puestos ocupados por los brasileños. ${ }^{61}$ Contribuían a aumentar la animosidad contra el Ejército Republicano las denuncias de corrupción en la línea sitiadora, donde según los informes de Hood, la población era obligada a vender el ganado para el consumo del ejército por papel moneda del Banco de Buenos Aires, mientras que los jefes vendían los cueros en metálico. ${ }^{62}$ En enero de 1827 Hood reafirmaba sus impresiones sobre la impopularidad de la guerra. En su opinión, los orientales estaban "divididos en infinidad de partidos, cada uno persiguiendo algún plan visionario", pero estaban "unidos" para alegar que se habían destruido los "móviles que antes los habían conducido a desear la anexión con la República de Buenos Ayres". En Buenos Aires, a su vez, también se hacían sentir voces que denunciaban los sacrificios que se estaban haciendo "por una inestable posesión como la que ofrecen los veleidosos y fluctuantes orientales". ${ }^{63}$

Ahora bien, el desarrollo de las operaciones militares y la conflictiva relación de los estados provinciales con el gobierno de las Provincias Unidas, en el marco de la exigencia brasileña de conservar el control de la ribera norte del Río de la Plata y las presiones de Lord Ponsonby para hallar una fórmula de paz, encontraron un punto de inflexión en mayo de 1827. En ese momento se llegó a un acuerdo preliminar para concluir la guerra sobre la base de la posesión de la Provincia por parte de Brasil. Como se sabe, esta convención no fue aceptada pese a las presiones

61 Barrán, Frega, Nicoliello, op. cit., p. 101-103. Hood a Ponsonby, 3 de diciembre de 1826.

62 Ibid., p. 105-107. Hood a Ponsonby, 15 de diciembre de 1826. Excede ampliamente a los alcances de este trabajo el análisis de la política monetaria de los gobiernos de Buenos Aires, así como la determinación de la veracidad o la falsedad de las acusaciones de fraude y corrupción en el ejército republicano.

63 Ibid., p. 111-112. Hood a Gordon, 5 de enero de 1827. 
de Ponsonby y las explicaciones dadas por el enviado del gobierno de Buenos Aires que había suscrito el arreglo, Manuel J. García. En el contexto del rechazo de las provincias al proyecto constitucional elaborado por el Congreso, la oposición a esta fórmula, que se producía incluso a poco más de dos meses de una importante victoria militar del Ejército Republicano en Ituzaingó, terminó provocando la dimisión de Rivadavia y la disolución del gobierno central. ${ }^{64}$

Interesa aquí llamar la atención sobre cómo fueron percibidas estas noticias en Montevideo y la campaña oriental. De acuerdo a lo informado por Hood, mientras que en la ciudad no habían causado "ninguna impresión sensible", en la zona controlada por los patriotas los efectos conmovieron a "todas las clases", llegándose a afirmar que se habían producido movimientos en la frontera para forzar el retiro de las tropas de Buenos Aires. En opinión del agente británico, una paz negociada de esta manera no tendría los efectos deseados sino que, por el contrario, fomentaría una guerra de recursos por tierra y por mar, donde era de temer que los corsarios se transformaran "en Piratas bajo la Bandera Oriental". Por último, Hood reafirmaba que la aspiración de "todas las clases" era "hacer de la Provincia Oriental un estado libre, independiente de todos los partidos", lo que era visto como "la única base inmediata y cierta sobre la cual se puede lograr la paz". ${ }^{65}$ Estaban muy próximos los recuerdos de dos circunstancias similares; la primera en octubre de 1811, donde un armisticio firmado por el gobierno de Buenos Aires con las autoridades españolas en Montevideo había cedido a éstas el control de los territorios al este del río Uruguay y parte del Entre Ríos; la segunda en 1816, cuando se acordaron los términos para una invasión portuguesa a la Provincia Oriental artiguista, tras la negociación en Río de Janeiro del mismo Manuel J. García. Ni el temor al "desorden social" que podía derivar del alejamiento del ejército

64 HALPERIN, Tulio. Argentina. De la revolución de independencia a la confederación rosista. Buenos Aires: Paidós, 1980, p. 238-239; Ferns, op. cit., p. 192-193. Juan E. Pivel Devoto sostiene una postura diferente al asumir como posibilidad que esta renuncia de las Provincias Unidas en favor del Emperador abría el camino a la independencia de la provincia, basándose en que la misma habría sido apoyada por Pedro Trápani, a quien llama "el director político de la revolución de 1825", "casi el padre de la revolución" (PIVEL, Juan E. Manuel José García y la independencia del Uruguay. Buenos Aires, 1940. Separata de Anuario de Historia Argentina, Buenos Aires: Sociedad de Historia Argentina, 1940).

65 Frega, Barrán, Nicoliello, op. cit., p. 121-122. Hood a Gordon, 26 de julio de 1827. 
republicano podía frenar la reacción frente a lo que consideraban una "entrega" o una "traición".

En Londres, un extenso artículo en The Times cuestionó los términos de lo acordado por García - sólo podía comprenderse si la República estuviera desfalleciente, pues se estaba dejando al comercio de Buenos Aires expuesto a la acción de corsarios o navíos de guerra apostados en Montevideo - y expresó su confianza - o deseo - de que el tratado no hubiera sido negociado con la complicidad o el consentimiento del Gabinete Británico. ${ }^{66}$ Desde Buenos Aires, The British Packet reafirmó la importancia estratégica de la posesión de la Banda Oriental y también tomó distancia de un posible apoyo que Gordon o Ponsonby hubieran prestado a un acuerdo de esa naturaleza, declarando: "No permitamos que el gobierno inglés se mezcle en la cesión de un solo palmo de la Banda Oriental a los portugueses, cosa que nos acarrearía el odio de toda Sud América". ${ }^{67}$

En Montevideo, el partido de los "imperialistas" aprovechó la ocasión para alimentar el "antiporteñismo". Antes de conocer las condiciones de lo acordado por García en Río de Janeiro, en las páginas del Semanario Mercantil de Montevideo se informó de un supuesto plan alternativo que estaba siendo puesto en práctica desde Buenos Aires como medida preventiva ante un eventual fracaso de la negociación. ${ }^{68}$ El artículo resaltaba la debilidad del gobierno central, en momentos en que muchas provincias habían retirado sus diputados del Congreso y podía temerse que los pueblos no aceptaran los términos del acuerdo. Según una carta enviada desde Buenos Aires, agentes de ese gobierno estaban procurando lograr que los orientales se pusieran "bajo los auspicios de Inglaterra". Si era un pronunciamiento "por la boca de los mismos Orientales", se decía, los pueblos no se opondrían, las fuerzas militares podrían retornar para contener a quienes no aceptaran la autoridad del gobierno central y se evitaría tener que pagar una indemnización al Imperio. Confiando en que Gran Bretaña no podría aceptar tal propuesta por los lazos de amistad

66 The Times, Londres, 28 de setiembre de 1827, p.2. No aventuraba opinión sobre el futuro del conflicto, en tanto ninguno de los contendientes parecía contar con los recursos necesarios para sostenerlo.

67 The British Packet, op. cit., p. 55 (artículo fechado el 17 de noviembre de 1827).

68 Semanario Mercantil de Montevideo, n. 44, 16 de junio de 1827, p. 184-186 ("Tiró el diablo de la manta y descubrióse el pastel"). Agradezco a Wilson González haberme facilitado una copia de este periódico. 
que mantenía con Portugal y Brasil, el articulista acusaba a los "argentinos" de carecer de "afecto verdadero por su Patria" y prevenía a los "incautos orientales" de "la borrasca de la revolución que han agitado los anarquistas Porteños". Se apelaba a los sentimientos "antiporteñistas" y al "miedo a la anarquía" para convocar a los "verdaderos orientales" a vivir "al abrigo de su Emperador constitucional". ${ }^{69}$

Los cambios políticos e institucionales en Buenos Aires repercutieron en la Provincia Oriental. Juan Antonio Lavalleja, que el año anterior había sido obligado a resignar el mando como gobernador por la Sala de Representantes, en octubre de 1827 procedió a la disolución de ese cuerpo. ${ }^{70}$ En la versión de Hood, los enfrentamientos entre el poder civil y el poder militar, "lejos de reconciliar las opiniones en conflicto, han producido sólo una mayor división de partidos, y han arrojado al país a toda clase de desorden, interiga y desconfianza" ${ }^{\prime \prime}$

A comienzos de 1828, el Cónsul británico lamentaba no poder obtener mayor información sobre los "verdaderos sentimientos" de la población, debido a que "cansados de la prolongación de la guerra, desean la paz casi en cualquier término, y por lo tanto se han vuelto completamente pasivos en política". ${ }^{72}$ A continuación agregaba: "En la campaña sabemos un poco más, que ellos están igualmente cansados de la guerra, pero dominados por la soldadesca que desea continuarla por el saqueo". En los siguientes despachos, la atención se centró en las divisiones de los jefes orientales y las posibilidades de conformar un gobierno estable. En marzo de 1828, por ejemplo, consignó la presencia de Fructuoso Rivera en la Provincia: "nos inclinamos a creer que él viene como el sucesor de Artigas y como el único jefe militar de la provincia". ${ }^{73}$ Aún cuando el desarrollo de los acontecimientos marcó otros rumbos - la campaña de Rivera en la Misiones Orientales - las anotaciones del cónsul británico brindan pistas sobre las realineaciones de fuerzas que se estaban produciendo. Sugería que

69 Semanario Mercantil de Montevideo, n. 58, 22 de setiembre de 1827, p. 245-247.

70 Pivel, Uruguay..., p. 468-471; y CUADRO, Inés. Viejas y nuevas prácticas políticas en la Provincia Oriental durante las guerras de independencia del Imperio del Brasil (1825-1828). In: I Congreso Latinoamericano de Historia Económica/IV Jornadas Uruguayas de Historia Económica (CD-ROM), Montevideo, AUDHE, 2007.

71 Barrán, Frega, Nicoliello, op. cit., p. 125-126. Hood a Gordon, 22 de octubre de 1827. Énfasis en el texto original.

72 Ibid., p. 135-136. Hood a Gordon, 2 de febrero de 1828.

73 Ibid., p. 139. Hood a Gordon, 5 de marzo de 1828. 
Rivera contaba con el apoyo del gobernador de Buenos Aires, "particularmente para frenar las ambiciones del General Lavalleja, quien se ha vuelto últimamente casi independiente de Buenos Ayres", y quizás más probablemente, con miras a establecer a un nativo [de la provincia] con infinitamente más influencia que Lavalleja a la cabeza de un Partido provincial". ${ }^{74}$

El 27 de agosto de 1828, finalmente, se firmó en Río de Janeiro una Convención Preliminar de Paz. Por este acuerdo, el Emperador del Brasil y el Gobierno de la República de las Provincias Unidas declararon su voluntad de que la Provincia de Montevideo (Cisplatina) se constituyera en un estado libre e independiente. Dispusieron también los términos en que se debía desalojar el territorio por parte de ambos beligerantes, así como el nombramiento de un gobierno provisorio, la aprobación de una constitución y el apoyo a la estabilidad del nuevo estado. En una cláusula adicional, las partes contratantes se comprometieron a garantizar que la "navegación del Río de la Plata y de todos los otros que desaguan en él" - léase Paraná y Uruguay - "se conserv[ara] libre para el uso de los súbditos de una y otra nación, por el tiempo de quince años" ${ }^{75}$ El canje de las ratificaciones debía realizarse en Montevideo, lo que ocurrió el 4 de octubre siguiente. En su informe, el cónsul señaló el envío de una notificación oficial al Ejército Republicano apostado cerca de Montevideo sobre el fin de las hostilidades, la liberación de los prisioneros y la distribución "en las calles" de copias del convenio. Resaltaba que no se habían realizado festejos públicos ni manifestaciones de complacencia por el término de la guerra, atribuyendo esa apatía a "la desconfianza en el nuevo gobierno". ${ }^{76}$ Ello contrastaba con lo que había acontecido en Buenos Aires con motivo de la llegada de los comisionados con el texto a ratificar, quienes fueron recibidos en medio de "entusiastas vivas". ${ }^{77}$ Debe tenerse presente que para quienes se habían mantenido fieles al dominio brasileño, por más que la Convención estableciera un "olvido" de las posiciones que

74 Ibid., p. 141-142. Hood a Gordon, 24 de marzo de 1828.

75 Armand Ugon, Cerdeiras Alonso, Arcos Ferrand, Goldaracena, op. cit., p. 84-89.

76 Barrán, Frega, Nicoliello, op. cit., p.143. Hood a Bidwell, 4 de octubre de 1828. Agregaba que aún no había recibido la notificación oficial de estilo. Mientras tanto, según informaba el representante estadounidense en Buenos Aires, Woodbine Parish se había trasladado con la comitiva a efectos de presenciar el canje como encargado de negocios de la potencia mediadora (Forbes, op. cit., p. 500).

77 The British Packet, op. cit., p. 198-199 ("La Paz", artículo publicado el 27 de setiembre de 1828). 
se habían sostenido con anterioridad a la firma de la paz, tenían razones para pensar que podían ser desplazados de las esferas del poder. Un aspecto interesante son las distintas versiones de las bases del acuerdo que fueron manejadas hasta la publicación del documento ratificado. Otras fórmulas - aspiraciones de deseos o expresiones de los temas que habían complicado la negociación se incluyeron entre las efectivamente acordadas como, por ejemplo, la garantía de Gran Bretaña a la libre navegación del Río de la Plata por cierto lapso ${ }^{78}$, la independencia de la Banda Oriental por quince años, la firma de Lord Ponsonby como garante por parte de Inglaterra ${ }^{79}$, o la consideración del "Estado de la Banda Oriental" como una de las partes contratantes. ${ }^{80}$

La correspondencia de Hood con Ponsonby en la etapa posterior a la ratificación de la Convención permite conocer la realineación de fuerzas que se produjo en la Provincia. En su opinión, si bien en Montevideo habían prevalecido "los amigos de Lavalleja" en la elección de representantes, en la campaña predominaban "los amigos de [José] Rondeau", por lo que estimaba que sería electo gobernador provisorio. ${ }^{81}$ Otro tema de fricción fue el tesoro de la Provincia, denunciando que los brasileños se habían llevado los fondos del Consulado y habían dispuesto rebajas en las tasas aduaneras para que las mercaderías fueran despachadas antes del cambio de gobierno. ${ }^{82}$ También quedaba pendiente el destino de las tropas desmovilizadas, especialmente el Ejército del Norte, del cual Fructuoso Rivera era el jefe de su vanguardia. Los informes de Hood, muestran el creciente peso de Rivera, indicando que

78 Ibid., p. 195-198 (artículo del 20 de setiembre de 1828).

79 The Times, Londres, 25 de octubre de 1828, p. 4 ("Money-Market and City Intelligence"). Las noticias fueron extractadas de cartas privadas provenientes de Río de Janeiro.

80 The Times, Londres, 24 de noviembre de 1828, p. 2. La publicación del texto de la Convención no incluyó la cláusula adicional sobre la navegación del Río de la Plata. Ello podría avalar la interpretación de que no era éste un interés especial de Gran Bretaña - que ya gozaba de ese derecho por su tratado con las Provincia Unidas sino una preocupación de Brasil, por las consecuencias del abandono de Montevideo y Colonia (The Times, 20 de diciembre de 1828, p. 2. "Money-Market and City Intelligence/Brazil and Buenos-Ayres").

81 Barrán, Frega, Nicoliello, op. cit., p. 145-146. Hood a Ponsonby, 29 de octubre de 1828. Las elecciones fueron conflictivas, en tanto se discutió sobre cuál reglamento - el de los orientales o el de los brasileños - debía ordenar el acto electoral. Véase también la nota del 15 de noviembre de 1828 (ibid., p. 147-148).

82 Ibid., p. 149-150. Hood a Ponsonby, 2 de diciembre de 1828. El cónsul informaba con orgullo que ningún comerciante británico había aceptado despachar mercaderías en esas condiciones, que procuraban dejar al nuevo gobierno sin medios de donde obtener recursos en forma inmediata. 
presumiblemente sería nombrado Comandante en Jefe del ejército "para asegurar su influencia sobre las clases bajas en el interior y con los soldados".83

Tras la reanudación de los conflictos en las Provincias Unidas en diciembre de 1828, Hood recibió instrucciones de Ponsonby a efectos de desalentar cualquier posibilidad de que el flamante nuevo estado pudiera involucrarse "directa o indirectamente en el apoyo o fomento de las facciones que ahora ultrajan el nombre de Gobernadores de Buenos Ayres". El agente británico enfatizó las ventajas de la salida independentista y apeló a los beneficios que ello tenía en esa coyuntura. En su opinión, debían mantenerse distantes de todos los partidos y bandos, y aprovecharse de las ventajas que tenían "para fortalecer su intercambio comercial con las partes de arriba del Río de la Plata que est[aban] separadas de Buenos Ayres por la guerra intestina". ${ }^{84}$

\section{$* * *$}

En las páginas anteriores se expusieron las posiciones y actitudes del cónsul y los comerciantes británicos en Montevideo, que dejaban entrever las diferentes miradas sobre la situación y el desarrollo del conflicto en un lugar que, si bien considerado estratégico, no tenía participación directa en la toma de decisiones sobre su destino político. Resulta particularmente importante, aún a pesar de las dificultades señaladas por Hood para obtener informaciones veraces, la percepción de los diversos intereses que pudieron encontrar un cauce en la salida independentista. Según el cónsul británico, el rechazo a brasileños y porteños casi por igual que se fue afirmando a medida que se prolongaba el conflicto respondía a motivos y objetivos diferentes según el grupo social que se considerara. Además de las "clases bajas de los criollos", que en opinión del cónsul lo que pretendían era la "anarquía", al señalar el viraje de los jefes militares sugería que ello obedecía a su

83 Ibid., p. 151. Hood a Ponsonby, 19 de diciembre de 1828. También se le habría ofrecido a Rivera comandar una expedición a Paraguay, contra el "despotismo" de Gaspar Rodríguez de Francia y para "abrir el comercio", la que rechazó. Sobre estos planes, véase The British Packet, op. cit., p. 202-205 (artículo del $1^{\circ}$ de noviembre de 1828); y The Times, Londres, 30 de enero de 1829, p. 2 (“Money-Market and City Intelligence", donde se transcriben noticias de Buenos Aires del 12 de noviembre). Sobre la posición de Rivera, véase FREGA, Ana, Conflictos fronterizos en la conformación estatal, 1828-1830. Cadernos do Centro de História e Documentação Diplomática, Río de Janeiro, año 5, número especial, 2007, p. 33-56.

84 arrán, Frega, Nicoliello, op. cit., p. 153. Hood a Bidwell, 26 de febrero de 1829. 
aspiración por conservar su posición preeminente, y en lo referente a los grupos mercantiles, sostenía que procuraban una salvaguarda ante la eventualidad de que sus intereses fueran "sacrificados" en favor del "engrandecimiento" de Buenos Aires. No eran ajenas a este cambio de posiciones la fluctuante situación política en la región y las presiones de la diplomacia británica. Por supuesto que hay que indagar más profundamente sobre la compleja trama de alianzas en el período, pero del repaso de esta documentación parece confirmarse que, tal como sugería Barrán en el artículo citado, en 1828 no se produjo la concreción de un objetivo proclamado en forma unánime en el levantamiento de 1825, sino un realineamiento de fuerzas sociales y políticas en favor de la independencia absoluta, entendida ella misma de modo diferente por quienes concurrieron a declararla o aceptarla. 